\title{
Agreement of Predicted 305-Day Milk Yields Relative to Actual 305-Day Milk Weight Yields
}

\author{
M. A. Quist, ${ }^{\star 1}$ S. J. LeBlanc, ${ }^{\star}$ K. J. Hand,† D. Lazenby,† F. Miglior, $¥ \S$ and D. F. Kelton* \\ *University of Guelph, Ontario Veterinary College, Guelph, Ontario, Canada, N1G 2W1 \\ †CanWest Dairy Herd Improvement Corporation, Guelph, Ontario, Canada, N1K 1E5 \\ $\ddagger$ Agriculture and Agri-Food Canada, Dairy and Swine Research and Development Centre, Sherbrooke, Quebec, Canada, J1M $1 Z 3$ \\ §Canadian Dairy Network, Guelph, Ontario, Canada, N1G 4T2
}

\begin{abstract}
The objectives of this study were to compare the multiple trait prediction (MTP) model estimate of 305-d lactation yield with the 305-d daily milk yield data from on-farm automated meters and software and to examine the accuracy of electronic identification (ID). Twenty-four-hour milk and component yields are calculated by using milk weights and samples collected 8 to 10 times/yr by Dairy Herd Improvement (DHI) organizations. Daily milk weights were collected from cows on 20 Canadian farms that used parlor milking systems with electronic ID and that were enrolled in a regular DHI program. A total of 10,175 DHI test days from 1,103 cows with complete 305-d lactation yields were entered into the MTP model, and lactation yields were predicted. Test days were grouped into first, second, and third and greater lactations and within each lactation group, days in milk were categorized in 3 stages (5 to 60, 61 to 120 , and 120 to $305 \mathrm{~d}$ in milk) for a total of 9 classes. Agreement analysis was used to compare the 305-d sum of daily milk to the MTP 305-d lactation yield predictions by using inputs from test days throughout the lactations. Results indicated that the MTP model overestimated lactation yields across all parity groups, ranging from 310 to $1,552 \mathrm{~kg}$ in parity 1,640 to $2,000 \mathrm{~kg}$ in parity 2, and 567 to $1,476 \mathrm{~kg}$ in parity 3 and greater. A preliminary examination of electronic ID accuracy was conducted on 4 farms. Two electronic ID systems were examined for cow ID accuracy by verifying the ID number appearing in the parlor with the corresponding ear tag number. There were no ID errors on 3 of 4 farms tested and only a very small number of errors $(3 / 80)$ on the fourth farm, indicating that the electronic ID systems used in milking parlors identify cows accurately.
\end{abstract}

Received December 11, 2006.

Accepted June 21, 2007.

${ }^{1}$ Corresponding author: mquist@uoguelph.ca
Key words: multiple-trait procedure, daily milk weight, electronic identification, electronic milk meter

\section{INTRODUCTION}

To assist in the management and efficiency of growing herds, more farms have implemented on-farm technology (Funk, 2002). Many large herds have incorporated automation in the milking parlor, including electronic cow identification (ID) and electronic milk meters to record individual cow milk yields at every milking (Averdunk et al., 1998).

For these computerized parlor systems to be effective, it is important that individual cows are identified accurately so that data collected in the milking parlor are correctly associated with the cow and any decisions and actions made by the producer are applied to the correct animal. Cows wear a transponder, commonly placed on a neck collar or ankle strap, which is programmed with their ID number. The transponder is read automatically in the parlor, either on entry or at each milking stall, and information about the cow is transmitted to the on-farm computer system.

Estimates of milk yield are useful for producers making management and breeding decisions, and are essential for genetic evaluation. Traditionally, the DHIA collects milk samples for analysis and milk weights of individual cows at 1 to 3 of the daily milkings over a 24$\mathrm{h}$ period at regular intervals 8 to 10 times throughout lactation. The resulting information is reported to the producer for use in management decisions. Currently, the multiple trait prediction (MTP) model is used in Canada to calculate phenotypic lactation curves (Schaeffer and Jamrozik, 1996) and requires an estimate of the 24-h milk yield from an individual cow at a particular DIM.

The objective of this study was to compare traditional MTP model-estimated 305-d milk yields with the actual 305 -d total milk yield measured on farms with automated meters to evaluate the accuracy of the MTP model estimation at different stages of lactation. In 
addition, the accuracy of electronic ID systems was examined.

\section{MATERIALS AND METHODS}

\section{Electronic Milk Meter Data Collection}

Participants were selected based on their willingness to provide access to daily milk records. A total of 20 farms in 4 Canadian provinces contributed data: 8 from Ontario and 12 from Manitoba, Alberta, and British Columbia; the latter 3 provinces are collectively referred to as Western Canada. Requirements for inclusion were enrollment in CanWest DHI milk recording (CanWest DHI, Guelph, Ontario, Canada) and being equipped with CanWest DHI-approved electronic milk meters and automatic cow ID in the milking parlor, which were interfaced with Dairy Comp 305 (Valley Agricultural Software, Tulare, CA). Daily milk weights were collected from each cow at every milking and stored on the farm computer. Data collection took place over more than 18 mo, from September 2004 to March 2006. Complete lactation data consisted of records in which milk recording began at 5 DIM and continued until 305 DIM. The goal of the daily milk weight collection was to gather full lactation data on individual cows and sum the daily yields to provide full lactation yield. Daily milk weight data were retrieved twice monthly by DHIA staff and stored on the DHIA network for further analysis. During this collection period, farms continued with regular DHIA tests.

\section{Data Handling and Software}

All 305-d production predictions generated by the MTP model at each regular test day were merged with the total lactation milk yield, summed from the collection of daily milk weights for each cow. Data were exported into the Statistical Analysis Software (Version 8, SAS Institute, 2000) program for analysis. Milkings missing from the daily milk data set were estimated by using nonparametric local regression techniques, via PROC LOESS in SAS (SAS Institute, 2000). The data were divided into 3 classes based on lactation number $(1,2$, and $\geq 3)$. Within each lactation group, DIM were categorized in 3 stages of lactation classes [5 to 60 (early), 61 to 120 (mid), and 121 to 305 DIM (late)], for a total of 9 classes, and analyzed separately.

\section{Agreement Analysis}

Initially, a scatter plot of the MTP model lactation yield estimate vs. actual lactation yield was generated around a line of agreement to observe the pattern and any obvious outliers. The agreement line was calculated by regressing actual yield on MTP model yield by using PROC REG (SAS Institute, 2000). An agreement analysis was carried out by examining the intercept and slope, along with their corresponding 95\% confidence intervals $(\mathbf{C I})$, and a concordance correlation coefficient was calculated as a measure of agreement. A slope equal to 1 and intercept equal to 0 would indicate perfect agreement between the MTP-estimated yield and actual yield. The intercept is a measure of bias, indicating the over- or underestimation of the MTP model predictions.

The concordance correlation coefficient $\left(r_{c}\right)$ proposed by Lin (1989) was used to measure the agreement between MTP model-estimated yields and actual 305-d yields. This correlation coefficient was used because it measures association as well as agreement. The range of values for the concordance correlation is -1 to 1 , and the closer the value is to 1 , the closer the agreement. Residuals were examined and $95 \%$ tolerance intervals were calculated as the difference between the actual 305-d lactation yield and the MTP model estimates.

To verify that the study herds were representative of their regions, the 12-mo averages of milk production from the study herds were calculated and ranked by percentiles against all DHIA herds in Ontario and Western Canada. Furthermore, average lactation curves of the study herds were compared with regional standard lactation curves from DHIA. These standard DHIA lactation curves were created by using lactation data from all cows in the DHIA program within a specified region.

\section{Electronic ID Accuracy}

This part of the study was conducted at the cow level and involved 4 farms with parallel parlors equipped with electronic ID systems. Two milking systems were included in the study: 1) Bou-Matic (Madison, WI) and 2) Germania Dairy Automation (Waunakee, WI); 2 farms equipped with system 1 , and 2 farms equipped with system 2 . Each farm was observed by an operator for 2 milking periods. As individual cows entered stalls in the parlor, their ID number, programmed into a transponder either on a neck collar or ankle strap, would appear on the individual stall display screen. The operator then checked the number appearing on the screen with the corresponding ear tag to verify that the correct ID number was being displayed. If a transponder was missing, it was not counted as an incorrect ID. The total number of incorrect ID and total number of cows milked were recorded.

Additionally, 10 farms participating in the daily milk weight study were users of the Bou-Matic Smart ID system. Smart ID technology is available in Bou-Matic 
parallel parlor designs and works by using techniques of pattern recognition to match milk weights if an ID transponder is not read during milking because of a lost ID tag or cow behavior at the entry of the parlor. Smart ID monitors cows to ensure that each is assigned a milk weight close to the expected milk weight in the event that more than one cow ID is missing at a given milking. After one side of a parallel parlor is finished milking, the Smart ID examines the data to see that all cows have a milk weight. If a cow was not identified, there will be an extra milk weight and the Smart ID technology is then engaged. Smart ID uses an algorithm that is able to compare each expected milk production in the group with the production at the stall the cow is standing in and the adjacent stall and then shifts the extra milk weight to best fit the expected production. Smart ID records were collected from these farms during the daily milk weight study period from September 2004 to March 2006. The frequency of Smart ID codes indicating the assignment of milk weights was calculated for each herd and for all herds combined.

\section{RESULTS}

\section{Daily Milk Yield and MTP Agreement Analysis}

Twenty farms from which daily milk weights were collected had full 305-d lactation data and regular DHIA test days for the time period. There were 1,103 cows with complete lactations, with a total of 10,175 test days from herds across Ontario and Western Canada. Of the 1,103 complete lactations, $9.65 \%$ of the milkings were missing.

The scatter plots indicated a number of outliers, and those animals were identified. It was discovered that some farms record daily milk weights in pounds and some in kilograms. All weights in pounds were converted to kilograms and this resolved the outliers in the scatter plots. There was a statistically significant correlation $(P<0.01)$ between MTP model estimates and actual yields for all 9 parity-stage of lactation classes. Results of the slope and intercept of the regression of the MTP model on yields measured daily, including 95\% CI, are shown in Table 1. The MTP overestimated 305-d milk yield more in early lactation (1,330 to $1,999 \mathrm{~kg}$ ) than in late lactation (332 to $640 \mathrm{~kg}$ ). Lactation 1 yield estimates were closer to actual yields, particularly by mid lactation. For lactations 2 and $\geq 3$, estimates improved, but actual yields were still consistently overestimated. Similarly, the results of the slope estimates were lower in early lactation and corresponding CI were wider than in later lactation. Only 2 CI, mid and late lactation of parity 1 , included 1 , indicating that the MTP yield estimates were equal to the actual yield. The late-lactation groups of lactations 2 and 3 came very close to including 1 , indicating that the MTP model estimates improved in later lactation across all parity groups. The highest agreement between MTP model estimates and actual yields was in late lactation, as indicated by concordance correlation values approaching 1 , with low agreement in early lactation (Table 1). Confidence intervals were wider in early lactation and decreased through mid and late lactation across all parities, indicating more accurate estimates in later lactation.

Milk production percentile values for the study herds in Ontario and Western Canada are found in Table 2. There was a wide range in average production across the study herds within both regions, with the Ontario percentiles ranging from 51 to 87 and the Western Canada percentiles ranging from 40 to 94 . The Ontario study herds were compared graphically with Ontario standard lactation curves (Figures 1 to 3 ), and the Western Canada study herds were compared with Western Canada (Manitoba, Alberta, and British Columbia curves averaged) standard lactation curves (Figures 4 to 6). The Ontario study herd lactation curves (Figures 1 to 3) were of the same slope as the industry provincial lactation curves, but with higher production across all parities. The lactation curves of study herds in Western Canada were practically identical to regional production curves (Figures 4 to 6 ).

\section{Electronic ID Accuracy Analysis}

System 1 milking systems had an ID error risk of 3 of $414(0.7 \%)$, whereas system 2 had no incorrect identifications (0/509). The proportion of corrected milk weights was calculated from ID system records collected from participating farms (Table 3). With all herds included, $0.86 \%$ of 1.45 million milk weights were corrected within the data collected from September 2004 to March 2006.

\section{DISCUSSION}

The regression intercepts and the concordance correlation coefficient analysis illustrate that, in general, the MTP model overestimated 305-d milk yield (Table 1) to a considerable extent in early lactation, but the MTP model estimated the yield more accurately in late lactation. The increasing accuracy of the MTP model estimations later in lactation is most likely due to the increase in the number of inputs into the MTP model as the number of test days accumulates. Schaeffer and Jamrozik (1996) support this view and reported that MTP model estimation accuracy depends on the number of test-day records available for input into the model. In calculating yield estimates, the MTP model incorpo- 
Table 1. Estimates of the intercept and slope, including the 95\% confidence intervals, of the regression of predicted milk yields on actual milk yields $(\mathrm{kg})$ and concordance correlations between multiple-trait prediction model yield estimates and actual yield with $95 \%$ confidence intervals

\begin{tabular}{|c|c|c|c|c|c|c|c|c|c|c|}
\hline \multirow[b]{2}{*}{ Lactation } & \multirow[b]{2}{*}{$\begin{array}{l}\text { Stage of } \\
\text { lactation }\end{array}$} & \multicolumn{3}{|c|}{ Intercept, kg } & \multicolumn{3}{|c|}{ Slope } & \multicolumn{3}{|c|}{ Concordance correlation } \\
\hline & & $\begin{array}{l}\text { Lower } \\
\text { limit }\end{array}$ & Estimate & $\begin{array}{l}\text { Upper } \\
\text { limit }\end{array}$ & $\begin{array}{l}\text { Lower } \\
\text { limit }\end{array}$ & Estimate & $\begin{array}{l}\text { Upper } \\
\text { limit }\end{array}$ & $\begin{array}{l}\text { Lower } \\
\text { limit }\end{array}$ & Coefficient & $\begin{array}{c}\text { Upper } \\
\text { limit }\end{array}$ \\
\hline \multirow[t]{3}{*}{1} & Early & 949.6 & $1,551.6$ & $2,153.6$ & 0.72 & 0.79 & 0.85 & 0.62 & 0.67 & 0.71 \\
\hline & Mid & -73.6 & 309.8 & 693.3 & 0.93 & 0.97 & 1.01 & 0.86 & 0.88 & 0.89 \\
\hline & Late & 218.8 & 332.2 & 445.7 & 0.97 & 0.99 & 1.00 & 0.94 & 0.94 & 0.95 \\
\hline \multirow[t]{3}{*}{2} & Early & 963.7 & $1,999.3$ & $3,035.0$ & 0.66 & 0.75 & 0.84 & 0.48 & 0.55 & 0.61 \\
\hline & Mid & $1,326.8$ & $1,897.4$ & $2,468.0$ & 0.77 & 0.82 & 0.87 & 0.79 & 0.82 & 0.85 \\
\hline & Late & 466.4 & 640.2 & 814.1 & 0.95 & 0.97 & 0.98 & 0.92 & 0.93 & 0.94 \\
\hline \multirow[t]{3}{*}{3} & Early & 474.3 & $1,329.8$ & $2,185.3$ & 0.76 & 0.83 & 0.90 & 0.57 & 0.62 & 0.66 \\
\hline & Mid & 979.1 & $1,475.6$ & $1,972.1$ & 0.84 & 0.88 & 0.92 & 0.83 & 0.85 & 0.87 \\
\hline & Late & 426.5 & 566.7 & 706.9 & 0.97 & 0.98 & 0.99 & 0.93 & 0.94 & 0.94 \\
\hline
\end{tabular}

rates previous test-day results; therefore, as DIM increase, more test-day data are available as input.

Many producers rely on first and second test-day results in early lactation to make inferences about the progress of a cow through the transition period. The use of daily milk weights for this purpose is more convenient and timely for observing daily progress (Sphar, 1993). The consequences of large yield overestimation and low agreement in early lactation are a cause for concern for producers relying solely on MTP model estimations from DHIA reports. The results of this study indicate that further refinement of the MTP model estimations in early lactation may be needed and may require adjustment to produce a more accurate lactation yield.

Table 2. Study herds in Ontario and Western Canada ranked by milk production percentile

\begin{tabular}{lcr}
\hline Herd & Percentile & Cows, n \\
\hline Ontario & & \\
A & 74.4 & 92 \\
B & 50.9 & 149 \\
C & 51.8 & 311 \\
D & 59.3 & 464 \\
E & 66.3 & 164 \\
F & 75.1 & 144 \\
G & 82.0 & 333 \\
H & 86.8 & 247 \\
Western Canada & & \\
I & 57.0 & 87 \\
J & 77.9 & 98 \\
K & 39.8 & 493 \\
L & 43.3 & 135 \\
M & 51.5 & 159 \\
N & 54.2 & 275 \\
O & 76.1 & 221 \\
P & 82.9 & 329 \\
Q & 85.6 & 103 \\
R & 90.3 & 121 \\
S & 92.2 & 267 \\
T & 94.3 & 147 \\
\hline
\end{tabular}

Cow numbers on the participating farms in both regions were larger than the regional mean; Ontario average herd size was 67 cows and Western Canada herd size was 117 (Canadian Dairy Information Centre, 2006). The variability in percentile rank for milk production (Table 2) indicates that these herds represent a range of high- and medium-producing herds in both study regions. This suggests that the extrapolation of study results to other dairy farms across Canada using electronic milk meters may be appropriate. The graphical display of average regional production and individual study herd average production (Figures 1 to 6 ) indicates that the shape of the lactation curves is similar across all lactations in both regions, yet the Western Canada study herds were more similar to average regional production across all lactations (Figures 4 to 6) than the Ontario herds (Figures 1 to 3 ).

Milk yields can be influenced by various factors, including geographical region, breed, diet, feeding, management, lactation number, season of calving, and DIM. The MTP model accounts for most of these production traits (excluding diet, feeding, and management) in the model when calculating lactation yield estimates. At the time the MTP was developed, standard lactation curves and production traits were derived for different areas of Canada by using production records from each region (Schaeffer and Jamrozik, 1996). Because of the steady change in the dairy industry in genetic selection, herd management, and technology, the production measures used in the MTP model are updated approximately every 2 yr to account for changes in the dairy industry. The inaccuracy of the MTP model in early lactation could be partly due to the high production average of the study herds in Ontario. It would be useful to analyze Western Canada and Ontario separately with additional data to assess the accuracy of the MTP estimations for each region. 


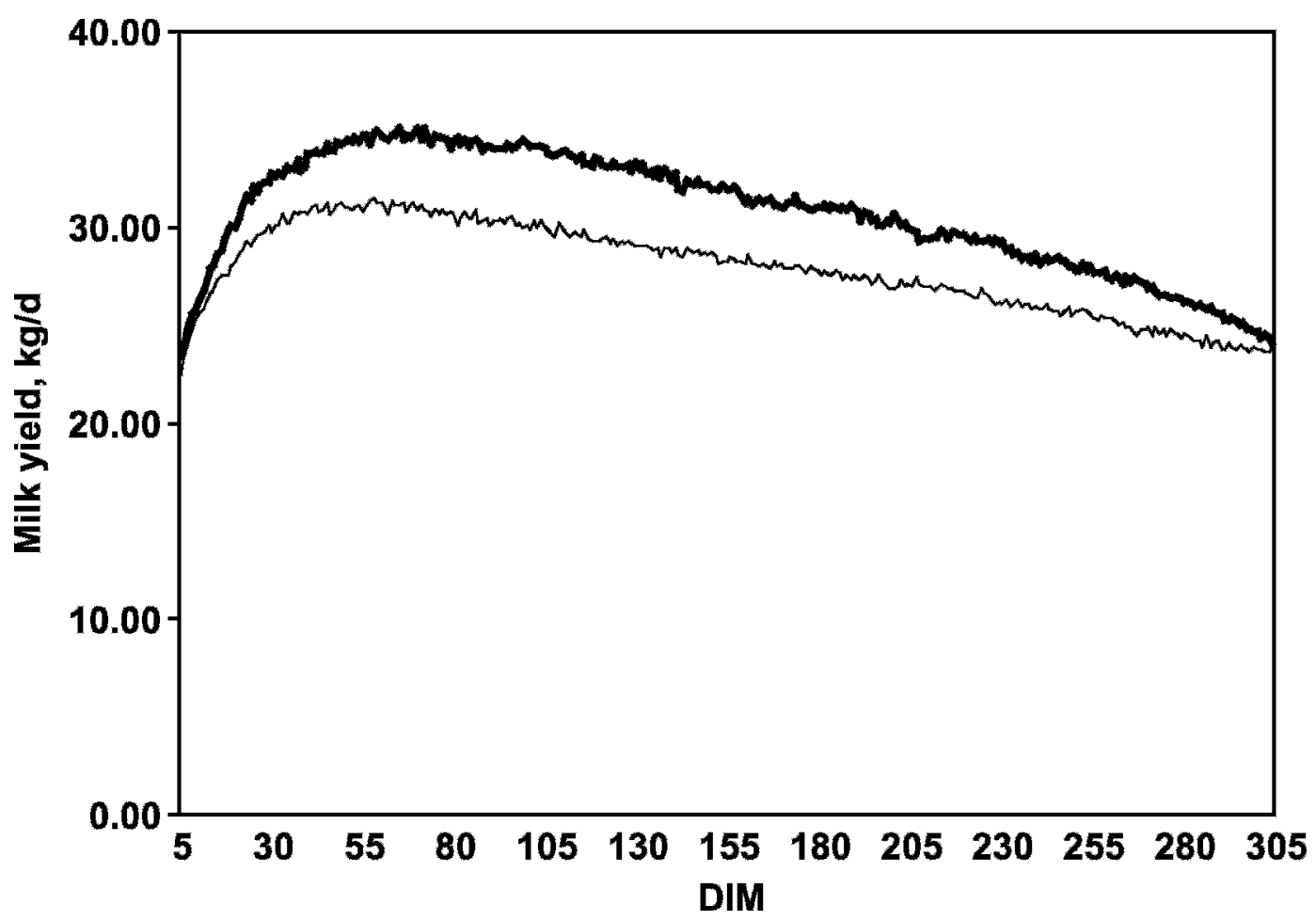

Figure 1. Comparison of average milk yield of Ontario study herds with standard lactation curves of lactation 1: Ontario standard lactation curve incorporating all Ontario DHIA herds of 2005 (thin line) and study herds (thick line).

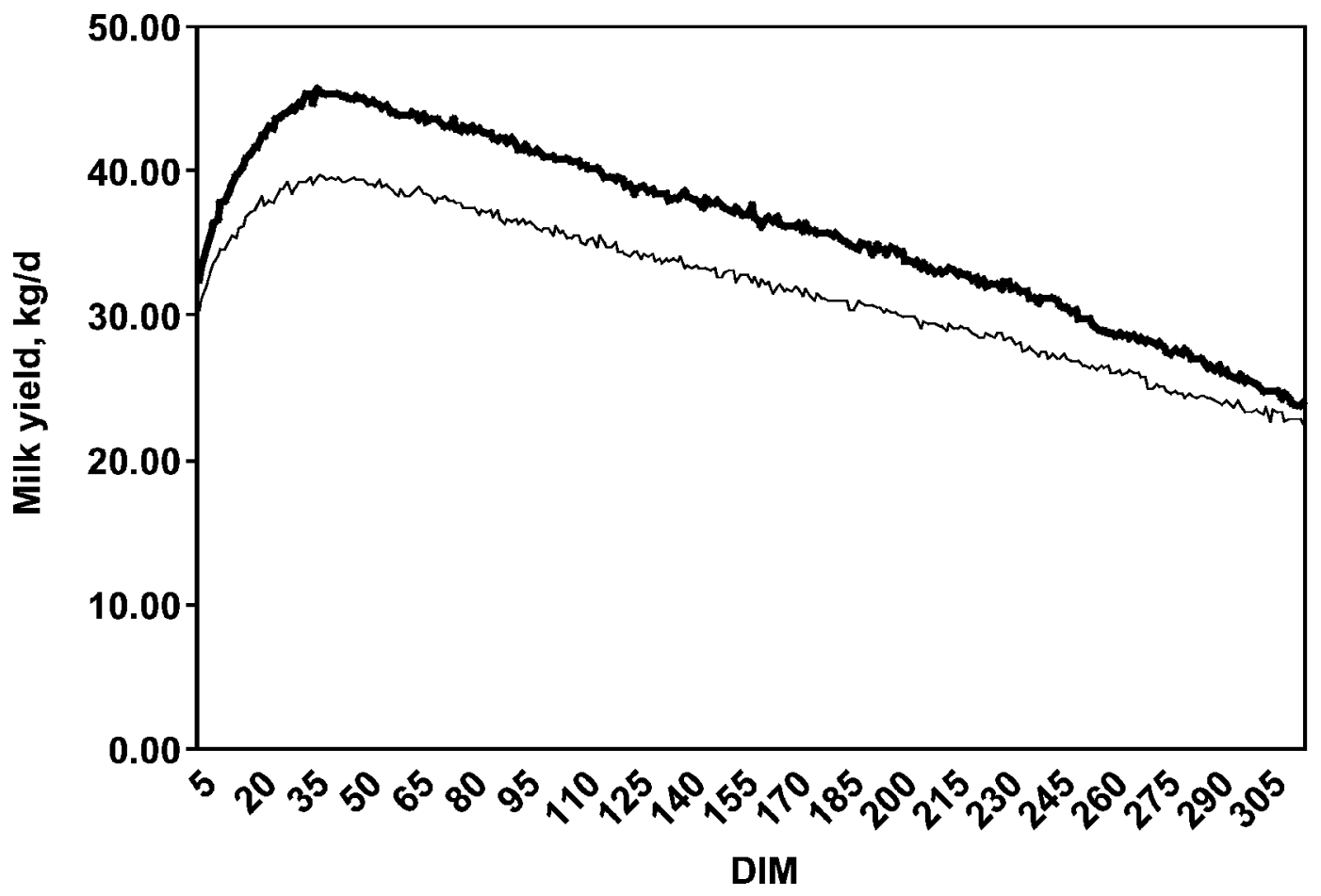

Figure 2. Comparison of average milk yield of Ontario study herds with standard lactation curves of lactation 2: Ontario standard lactation curve incorporating all Ontario DHIA herds of 2005 (thin line) and study herds (thick line). 


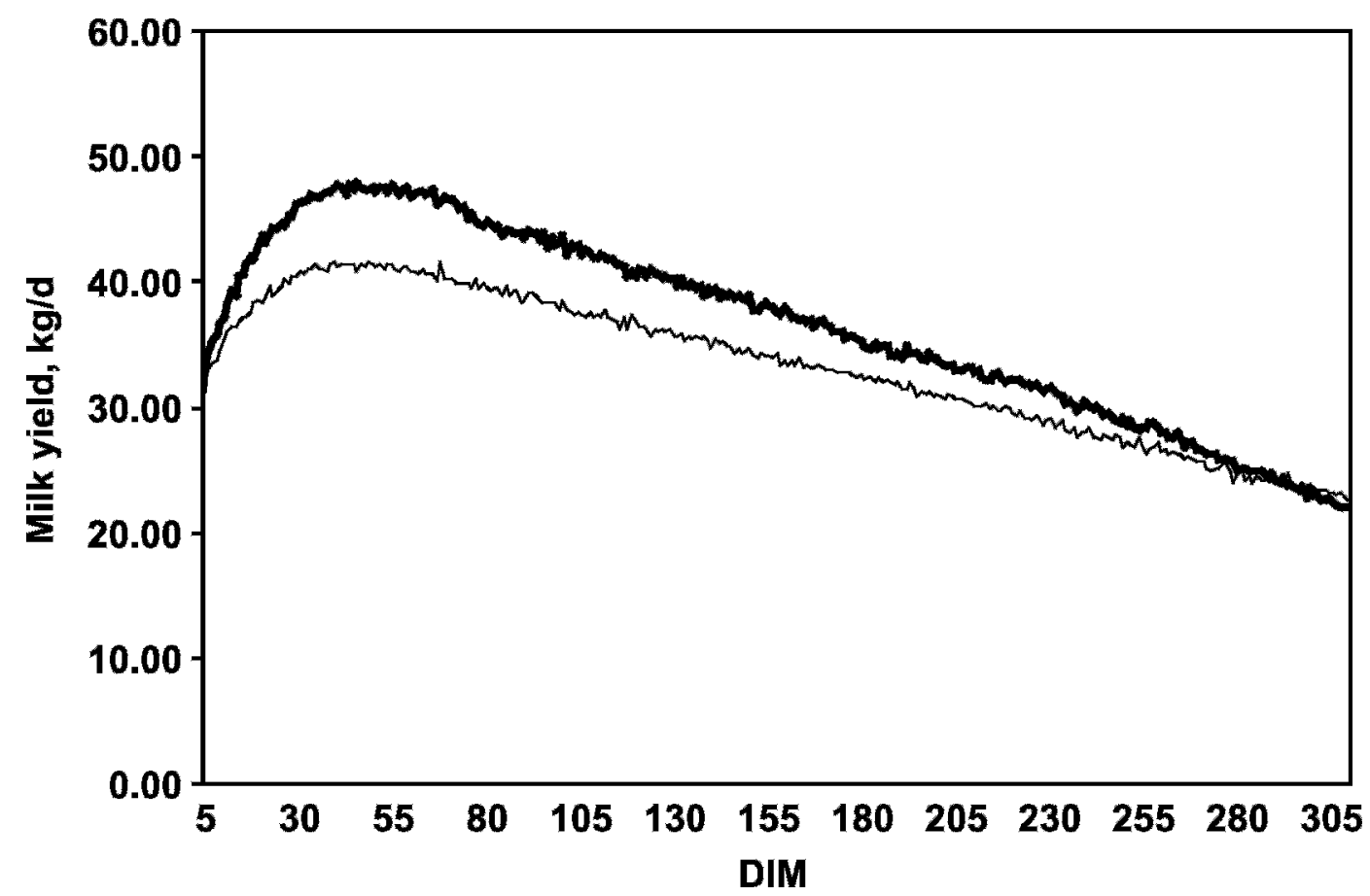

Figure 3. Comparison of average milk yield of Ontario study herds with standard lactation curves of lactation $\geq 3$ : Ontario standard lactation curve incorporating all Ontario DHIA herds of 2005 (thin line) and study herds (thick line).

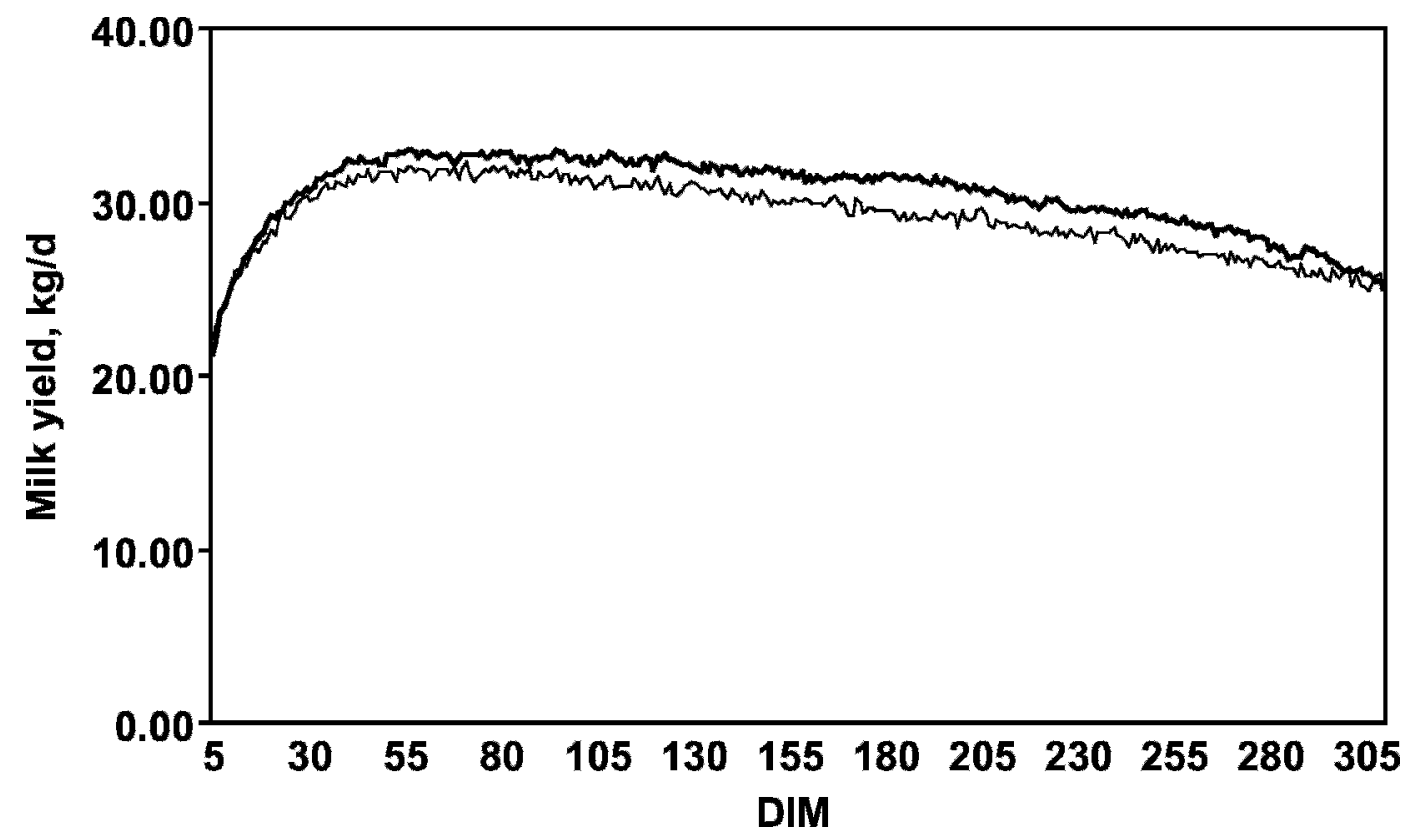

Figure 4. Comparison of average milk yield of Western Canada study herds with standard lactation curves of lactation 1: Western Canada standard lactation curve incorporating all British Columbia, Alberta, and Manitoba DHIA herds of 2005 (thin line) and study herds (thick line). 


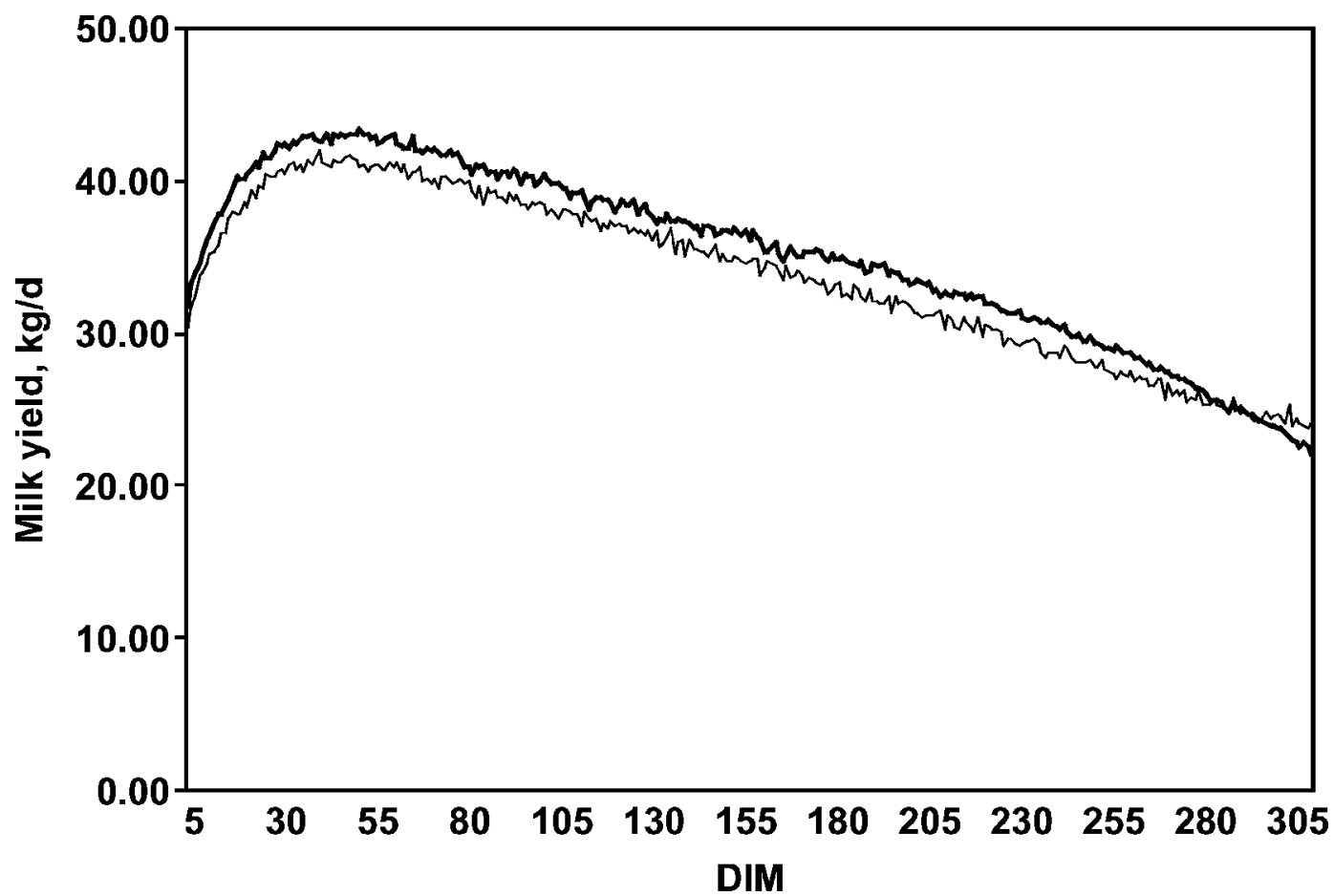

Figure 5. Comparison of average milk yield of Western Canada study herds with standard lactation curves of lactation 2: Western Canada standard lactation curve incorporating all British Columbia, Alberta, and Manitoba DHIA herds of 2005 (thin line) and study herds (thick line).

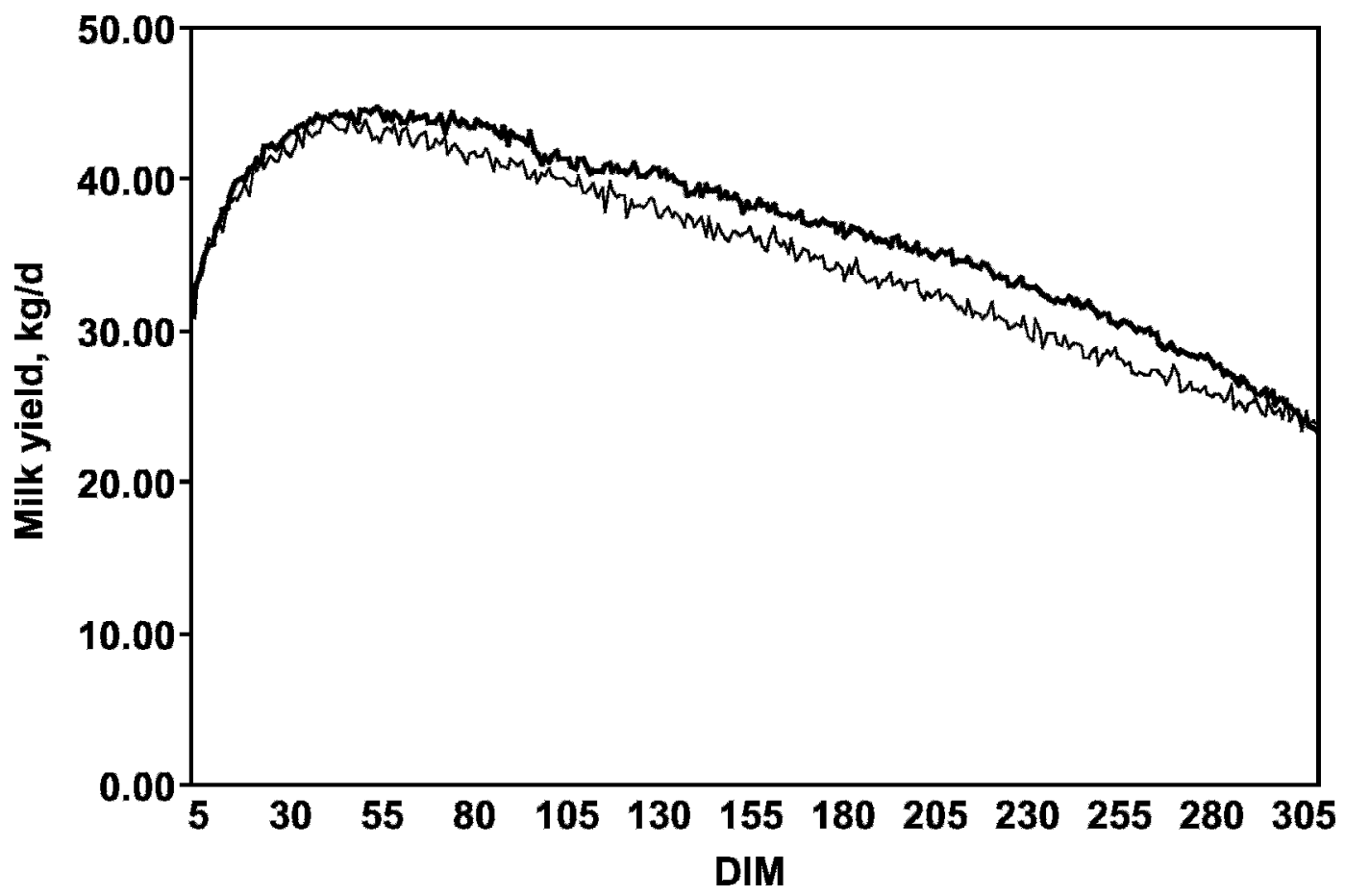

Figure 6. Comparison of average milk yield of Western Canada study herds with standard lactation curves of lactation $\geq 3$ : Western Canada standard lactation curve incorporating all British Columbia, Alberta, and Manitoba DHIA herds of 2005 (thin line) and study herds (thick line). 
Table 3. Occurrence of Smart ID use in 10 herds in Canada

\begin{tabular}{lcrc}
\hline & $\begin{array}{c}\text { Total } \\
\text { milkings } \\
\text { recorded, }\end{array}$ & $\begin{array}{c}\text { Smart } \\
\text { ID, n }\end{array}$ & $\begin{array}{c}\text { Smart } \\
\text { ID, \% }\end{array}$ \\
\hline $\mathrm{A}$ & 109,434 & 1,741 & 1.59 \\
$\mathrm{~B}$ & 25,069 & 98 & 0.39 \\
$\mathrm{C}$ & 63,764 & 1,774 & 2.78 \\
$\mathrm{D}$ & 375,478 & 3,861 & 1.03 \\
$\mathrm{E}$ & 90,474 & 193 & 0.21 \\
$\mathrm{~F}$ & 52,109 & 738 & 1.42 \\
$\mathrm{G}$ & 37,049 & 242 & 0.65 \\
$\mathrm{H}$ & 267,852 & 1,009 & 0.38 \\
$\mathrm{I}$ & 231,883 & 731 & 0.32 \\
J & 197,471 & 2,107 & 1.07 \\
Total/mean & $1,450,583$ & 12,494 & 0.86 \\
\hline
\end{tabular}

The MTP model is flexible with regard to the number and interval of test days entered into the model. Schaeffer and Jamrozik (1996) reported that the MTP model can handle any number of test days from 1 to 305 . Milking parlor systems often store daily milk weight data as multiple-day averages. Hand et al. (2006) included multiple-day milk yield averages (up to $14 \mathrm{~d}$ ) as input into the MTP, as an alternative to the traditional 24-h milk yield, to determine the best estimator of 24$\mathrm{h}$ milk yield to enter into the MTP model. The results suggested that there was no significant effect when multiple-day averages were entered into the MTP model as single-day, $24-\mathrm{h}$ milk yield estimates. Results from a recent survey of milk-recording countries reported that $22 \%$ of farms with electronic milk meters use multiple-day averages as a 24 -h milk yield estimate (Miglior et al., 2006). An advantage of using a multipleday average of daily milk weights is that it can avoid inputting a single test day in which yields are abnormally high or low because of anomalies in the weather, environment, or rations (Ng-Kwai-Hang et al., 1984).

A major concern in considering using electronic milk meter data as official records in DHIA is the reliability of the measurements (Koorn, 1998; Lefcourt, 1999; Bunger et al., 2004). CanWest DHI technicians annually check the calibration of electronic milk meters of herds on publishable testing schemes. If producers refuse the calibration check done by DHIA technicians, the data collected are not used as official production records within the dairy industry. The International Committee for Animal Recording (ICAR) has a Recording Devices Sub-Committee for approving milk volume measurement devices. This committee suggests annual examinations of electronic milk meters and provides guidelines on performing examinations for numerous types of meters provided by various milk equipment companies (ICAR, 2006). Currently, there is no published research investigating the accuracy of elec- tronic milk meter measurements, which is an important component of the reliability and accuracy of records.

An additional step to address the reliability of measurements is to ensure that milk weights are correctly assigned to cows in the milking parlor. The results of the electronic ID accuracy study suggest that the electronic ID systems used in these milking parlors were very accurate, with only 3 cows identified incorrectly out of a total of 1,432 (0.2\%) cows. Missing transponders were not included as incorrect ID, because there was no ID transponder to read.

The proportion of corrected milk weights from the ID system can quantify the occurrence of situations in which a single transponder or multiple transponders were missing from cows in the parlor. This is not an indication of how accurately the ID transponders are read, but rather the number of times measured milk weights were assigned to cows with no recorded ID at that milking. If the ID system had not been in place, up to $0.86 \%(12,494)$ of the milk weights could have been recorded for cows that had expected production that differed greatly from the attributed milk weight. Nevertheless, the range of engagement of the ID system among farms ( 0.2 to $2.8 \%$ of milkings) is notable and merits further description to determine whether this is a function of herd management or the ID system.

The aim of this study was to conduct a preliminary examination of the accuracy of electronic ID in milking parlors. Numerous approaches could be taken to conduct a larger scale study and investigate the factors that contribute to incorrect ID. Investigation at the herd level could account for environmental effects, such as herd management, holding area, and milking parlor design on individual farms, that contribute to ID inaccuracies. Sources of error to consider include incorrect cow ID programmed into the transponder and the condition and age of the transponders, as well as the configuration of the parlor and location of the portal entry archway. Increasing the number of milking periods in which ID are verified either at consecutive milkings (i.e., over $1 \mathrm{wk}$ ) or at regular intervals (i.e., 1/wk) could detect patterns of incorrect ID. Tracking the stall number and cow ID number of ID read incorrectly will help recognize repeated incorrect ID and perhaps explain the cause of the inaccuracies. Incorporating numerous farms could provide insight into more varied milking systems with electronic ID and management practices. Future investigation of ID accuracy should result in routine validation of the electronic ID of the milking systems. This would ensure that the milk weight data being collected are attributed to the correct animal. This could produce a "reliability score" given to a particular farm or milking system and would be incorporated 
into official record calculations related to cow ID (i.e., 305-d milk yield projection).

\section{CONCLUSIONS}

With the increasing number of farms investing in electronic milk meter equipment, it is necessary for DHIA organizations to accommodate their needs to maintain and encourage participation in milk-recording programs. Their continued participation is vital for the industry to continue to collect valuable information for the benefit of the farm and the broader dairy industry. The concordance correlation was a good indicator of the strength of agreement between the MTP model estimation and actual 305-d milk yield. Results suggest that the MTP model yielded more accurate estimates in later lactation across all parities. The linear regression results support the observation of increased accuracy later in lactation. This increase in accuracy of the MTP model yield estimates is most likely due to the increasing number of test days entered into the model. The use of daily milk weights as input into the MTP model at more frequent intervals than typical monthly DHIA test days could improve the accuracy of the MTP model estimation, which would be especially useful in early lactation for on-farm management decisions.

The results of this preliminary examination of electronic ID accuracy suggest that the 2 electronic ID systems used in milking parlors on the study farms identified cows accurately. Further research is needed at the herd level to investigate the accuracy of all milking systems offering electronic ID as well as the factors that contribute to incorrect ID before daily milk weight data are incorporated into the DHIA program.

\section{ACKNOWLEDGMENTS}

The authors thank DairyGen (Guelph, Ontario, Canada) and Natural Sciences and Engineering Research Council of Canada (Ottawa, Ontario, Canada) for funding this research. The participating producers, the staff and technicians at CanWest DHI, and the research technicians are gratefully acknowledged for their valuable assistance in collecting the data.

\section{REFERENCES}

Averdunk, G., J. Aumann, and J. Duda. 1998. Tendencies in AM/PM recording in Germany and non-conventional recording methods in the future. Pages 139-145 in EAAP Publ. 91: Proc. 31st ICAR Session Mtg., Rotorua, New Zealand. Eur. Assoc. Anim. Prod., Rome, Italy.

Bunger, A., K. Kuwan, F. Reinhardt, H.-U. Brahmstaedt, and R. Reents. 2004. Benefits from daily milk recording data. Pages 229235 in EAAP Publ. 113: Proc. 34th ICAR Session Mtg., Sousse, Tunisia. Eur. Assoc. Anim. Prod., Rome, Italy.

Canadian Dairy Information Centre. 2006. Subject: Enrollments on milk recording. http://www.dairyinfo.gc.ca/cdicfpmilkr.htm Accessed July 13, 2006.

Funk, D. A. 2002. Performance recording: Different strategies and breeders' needs. Pages 41-46 in EAAP Publ. 107: Proc. 33rd ICAR Session Mtg., Interlaken, Switzerland. Eur. Assoc. Anim. Prod., Rome, Italy.

Hand, K. J., D. Lazenby, F. Miglior, D. F. Kelton, and M. A. QuistMoyer. 2006. Use of daily milk weight to predict lactation and 24-hour yields. Pages 48-52 in Proc. 35th ICAR Session Mtg., Kuopio, Finland. Eur. Assoc. Anim. Prod., Rome, Italy.

International Committee for Animal Recording. 2006. Subject: Recording Devices. http://www.icar.org/pages/Sub_Committees/ sc_recording_devices.htm Accessed August 2, 2006.

Koorn, D. S. 1998. The introduction of a milk recording system based on milk yields of ICAR approved electronic milk meters and AT4 sampling for fat, protein and SCC. Pages 147-150 in EAAP Publ. 91: Proc. 31st ICAR Session Mtg., Rotorua, New Zealand. Eur. Assoc. Anim. Prod., Rome, Italy.

Lefcourt, A. M. 1999. Method to monitor the precision of milk yields recorded at individual milking stalls on daily basis. J. Dairy Sci. 82:953-956.

Lin, L. I. 1989. A concordance correlation coefficient to evaluate reproducibility. Biometrics 45:255-268.

Miglior, F., S. de Roos, Z. Liu, S. Mattalia, L. R. Schaeffer, A. Tondo, and P. VanRaden. 2006. Report of the ICAR working group on lactation calculation methods: A survey on milk recording strategies in dairy cattle. Pages 145-149 in Proc. of 35th ICAR Session Mtg., Kuopio, Finland. Eur. Assoc. Anim. Prod., Rome, Italy.

Ng-Kwai-Hang, K. F., J. F. Hayes, J. E. Moxley, and H. G. Monardes. 1984. Variability of test-day milk production and composition and relations of somatic cell counts with yield and compositional changes of bovine milk. J. Dairy Sci. 67:361-366.

SAS Institute. 2000. SAS/STATC User's Guide. Version 8. SAS Inst. Inc., Cary, NC.

Schaeffer, L. R., and J. Jamrozik. 1996. Multiple-trait prediction of lactation yields for dairy cows. J. Dairy Sci. 79:2044-2055.

Sphar, S. L. 1993. New technologies and decision making in high producing herds. J. Dairy Sci. 76:3269-3277. 